Published in final edited form as:

Sci Signal. ; 6(291): ra78. doi:10.1126/scisignal.2004143.

\title{
Regulation of Yeast G Protein Signaling by the Kinases That Activate the AMPK Homolog Snf1
}

\author{
Sarah T. Clement ${ }^{1}$, Gauri Dixit ${ }^{1}$, and Henrik G. Dohlman ${ }^{1,2,{ }^{*}}$ \\ 1Department of Biochemistry and Biophysics, University of North Carolina at Chapel Hill, Chapel \\ Hill, NC 27599, USA. \\ 2Department of Pharmacology, University of North Carolina at Chapel Hill, Chapel Hill, NC 27599, \\ USA.
}

\begin{abstract}
Extracellular signals, such as nutrients and hormones, cue intracellular pathways to produce adaptive responses. Often, cells must coordinate their responses to multiple signals to produce an appropriate outcome. We showed that components of a glucose-sensing pathway acted on components of a heterotrimeric guanine nucleotide-binding protein ( $\mathrm{G}$ protein)-mediated pheromone signaling pathway in the yeast Saccharomyces cerevisiae. We demonstrated that the G protein a subunit Gpa1 was phosphorylated in response to conditions of reduced glucose availability and that this phosphorylation event contributed to reduced pheromone-dependent stimulation of mitogen-activated protein kinases, gene transcription, cell morphogenesis, and mating efficiency. We found that Elm1, Sak1, and Tos3, the kinases that phosphorylate Snf1, the yeast homolog of adenosine monophosphate-activated protein kinase (AMPK), in response to limited glucose availability, also phosphorylated Gpa1 and contributed to the diminished mating response. Reg1, the regulatory subunit of the phosphatase PP1 that acts on Snf1, was likewise required to reverse the phosphorylation of Gpa1 and to maintain the mating response. Thus, the same kinases and phosphatase that regulate Snf1 also regulate Gpa1. More broadly, these results indicate that the pheromone signaling and glucose-sensing pathways communicate directly to coordinate cell behavior.
\end{abstract}

\footnotetext{
Copyright 2008 by the American Association for the Advancement of Science; all rights reserved.

*Corresponding author. hdohlman@med.unc.edu.

Author contributions: S.T.C. and H.G.D. designed the research; S.T.C. and G.D. performed the research; S.T.C., G.D., and H.G.D. analyzed the data; and S.T.C. and H.G.D. wrote the manuscript.

Competing interests: The authors declare that they have no competing interests.

SUPPLEMENTARY MATERIALS

www.sciencesignaling.org/cgi/content/full/6/291/ra78/DC1

Fig. S1. Phosphorylation of Gpa1 is not affected by nucleotide binding.

Fig. S2. Reg1 and Snf1 promote maximal mating responses.

Table S1. Yeast strains used in this study.

Table S2. Plasmids used in this study.

Table S3. Sequences of oligonucleotides used in this study.

References (50-53)
} 


\section{INTRODUCTION}

Hormones, neurotransmitters, odors, and environmental signals are commonly detected by heterotrimeric guanine nucleotide-binding protein (G protein)-coupled receptors (GPCRs). Upon ligand binding, the activated receptor causes the $G$ protein a subunit to release guanosine diphosphate (GDP), bind to guanosine triphosphate (GTP), and dissociate from the $\mathrm{G}$ protein $\beta \gamma$ subunit. This dissociation initiates an appropriate cellular response, which is commonly transmitted through the production of second messengers or the activation of a mitogen-activated protein kinase (MAPK) cascade (1). For example, the peptide hormone glucagon is produced in response to a reduction in the amount of glucose in the blood, and it stimulates the breakdown of cellular glycogen and the release of glucose into the circulation (2). Whereas the ability of specific GPCRs to control glucose metabolism is well established, less is known about how changes in glucose availability affect GPCR signaling.

$\mathrm{G}$ protein signaling cascades are highly conserved in animals, plants, and fungi. In the yeast Saccharomyces cerevisiae, peptide pheromones trigger a series of signaling events leading to the fusion of haploid $\mathbf{a}$ and a cell types. In mating type a cells, the a-factor pheromone binds to the GPCR Ste2, which is coupled to a G protein composed of Gpa1 (Ga), and Ste4 and Ste $18(\mathrm{G} \beta \gamma)$. The free $\mathrm{G} \beta \gamma$ dimer then activates a protein kinase cascade that culminates in activation of the MAPK Fus3 and, to a lesser extent, Kss1. Activation of the mating pathway leads ultimately to gene transcription, cell cycle arrest at the $\mathrm{G}_{1}$ stage, and morphological changes to form an a-a diploid cell (3).

In addition to activation by GPCRs, $\mathrm{G}$ proteins are regulated by post-translational modifications, which are often dynamic and contribute directly to signal transmission. For example, Gpa1 is modified by myristoylation, palmitoylation, ubiquitylation, and phosphorylation (4-7). In an earlier effort to identify the kinase that phosphorylates Gpa1, we screened 109 gene deletion mutants that represented most of the nonessential protein kinases in yeast. With this approach, we identified that the kinase Elm1 phosphorylates Gpa1. Under nutrient-rich conditions, Elm1 is present predominantly during the $\mathrm{G}_{2}-\mathrm{M}$ phase, and this leads to concomitant, cell cycle-dependent phosphorylation of Gpa1 (6).

In addition to phosphorylating Gpa1, Elm1 phosphorylates and regulates a number of proteins necessary for proper cell morphogenesis and mitosis (8). Elm1 is also one of the three kinases that phosphorylate and activate Snf1 (9), the founding member of the adenosine monophosphate-activated protein kinase (AMPK) family (10). Under conditions of limited glucose availability, Snf1 is phosphorylated (and activated) on $\mathrm{Thr}^{210}$ (11). Once activated, Snf1 promotes the transcription of genes that encode metabolic factors to maintain energy homeostasis (12-14). Here, we demonstrated that the G protein Gpal was likewise phosphorylated in response to the limited availability of glucose. Moreover, Gpa1 was phosphorylated and dephosphorylated by the same enzymes that act on Snf1. Under conditions that promoted the phosphorylation of Gpa1, cells exhibited a diminished response to pheromone, a delay in mating morphogenesis, and a reduction in mating efficiency. These findings reveal a previously uncharacterized direct link between the nutrient-sensing AMPK and $\mathrm{G}$ protein signaling pathways. More broadly, they reveal how metabolic and GPCR signaling pathways coordinate their actions in response to competing stimuli. 


\section{RESULTS}

\section{Gpa1 is phosphorylated in response to reduced glucose availability}

We previously showed that Elm1 phosphorylates Gpa1, and that phosphorylation is regulated in a cell cycle-dependent manner (6). Elm1 also phosphorylates Snf1, among other substrates; however, in this case, phosphorylation occurs in response to glucose limitation. Thus, we considered whether glucose availability affected the phosphorylation status of Gpa1. Because phosphorylation causes a change in the migration of a protein when resolved by SDS-polyacrylamide gel electrophoresis (SDS-PAGE), we performed Western blotting analysis with anti-Gpa1 antibodies of lysates of cells grown in medium containing 2 or $0.05 \%$ glucose to determine whether Gpa1 was phosphorylated. Indeed, we found that Gpa1 was phosphorylated (Fig. 1A), and that phosphorylation was rapid and sustained in cells cultured in medium with lower glucose concentration (Fig. 1B); however, Gpa1 was still phosphorylated in cells deficient in Elm1 (elm1 $\Delta$ mutant cells). Because two other kinases, Sak1 and Tos3, are also capable of phosphorylating $\operatorname{Snf} 1(9,15)$, we examined whether these kinases, alone or in combination, contributed to the phosphorylation of Gpa1 under conditions of limited glucose availability. Of the single kinase deletion mutants, sakl $\Delta$ cells exhibited the smallest increase in Gpa1 phosphorylation because of glucose limitation (Fig. 1C). Deletion of all three kinases was needed to eliminate Gpa1 phosphorylation at early time points (Fig. 1, B and D); however, limited phosphorylation of Gpa1 was detectable after 30 to $60 \mathrm{~min}$, indicating that another kinase was active during prolonged starvation. Under the same conditions, Snf1 remained inactivated, as reported previously $(9,15-17)$. It appeared that Snf1 did not phosphorylate Gpa1, because we detected phosphorylated Gpa1 in snfl $1 \Delta$ mutant cells cultured in low glucose, although the abundance of Gpa1 was reduced in these cells (Fig. 1E). These results suggest that Gpa1 is a substrate for the Snf1-activating kinases Elm1, Sak1, and Tos3.

Having shown that the kinases that phosphorylate Snf1 also phosphorylated Gpa1, we asked whether the phosphatase for Snf1, which consists of the subunits Glc7 and Reg1 (18), was capable of dephosphorylating phosphorylated Gpa1. Reg1 is the regulatory subunit of the phosphatase, and it recruits substrates to the catalytic subunit Glc7 (19). Because the gene encoding Glc7 is essential for yeast survival, we tested reg $1 \Delta$ mutant cells. Indeed, we found that the abundance of phosphorylated Gpa1 was increased in regl $1 \Delta$ compared to that in wild-type cells, and that Gpa1 remained phosphorylated even under conditions of abundant glucose concentration (Fig. 1, A and B). Together, these data suggest that the kinases and phosphatase that act on Snf1 are capable of acting on Gpa1 as well.

Snf1 exists as part of a heterotrimeric complex, and its phosphorylation is partially dependent on the presence of its $\beta$ subunit in the complex (20). Accordingly, we investigated whether the phosphorylation of Gpa1 required any of its known binding partners (21-23). To that end, we monitored the phosphorylation of Gpa1 in yeast strains lacking the GPCR (Ste2), the G protein $\beta$ subunit (Ste4), the guanosine triphosphatase (GTPase)-activating protein (GAP, Sst2), and the atypical G $\beta$ subunit and phosphatidylinositol 3-kinase (PI3K) regulatory subunit (Vps15) that are involved in Gpa1 activation and signaling. We found that Gpa1 was still phosphorylated in the absence of each binding partner, although the 
extent of phosphorylation of Gpa1 was diminished in cells lacking Ste 4 compared to that in wild-type cells (Fig. 1, F and G). The extent of phosphorylation of the GTP-bound (GTPasedeficient) $\mathrm{Gpa} 1{ }^{\mathrm{Q} 323 \mathrm{~L}}$ mutant form of Gpa1 was also slightly reduced compared to that in wild-type cells (fig. S1). These results suggest that, as is the case with Snf1, the phosphorylation of Gpa1 occurs most efficiently when it is in a heterotrimeric state.

Having shown that Sak1 is particularly important for the phosphorylation of Gpa1, we next investigated whether Sak1 directly phosphorylated Gpa1. We copurified Sak1 with Gpa1 from cells grown in medium containing either 2 or $0.05 \%$ glucose (Fig. 2A), suggesting that the Gpa1-Sak1 interaction was not glucose-dependent. To assess whether Sak1 was sufficient for Gpa1 phosphorylation, we conducted in vitro kinase assays. We found that the purified Sak1-TAP (tandem affinity purification) fusion protein phosphorylated purified recombinant Gpa1 protein (Fig. 2B), whereas the catalytically impaired Sak1 ${ }^{\text {D277A }}$ mutant did not. Thus, we conclude that Sak1 directly phosphorylates Gpa1.

Gpa1 was abundantly phosphorylated in regl $1 \Delta$ mutant cells even when they were maintained in medium with sufficient glucose (Fig. 1, A and G). We confirmed that Reg1 copurified with Gpa1 from cells grown in medium containing either 2 or $0.05 \%$ glucose (Fig. 2C); however, we were unable to purify recombinant Reg1 or Glc7 proteins in sufficient quantities to conduct an in vitro phosphatase assay. As an alternative, we purified recombinant Gpa1 and Reg1 proteins and resolved them by steric exclusion chromatography. Gpa1 eluted in two distinct peaks: the first representing monomeric Gpa1, and the second representing Gpa1 in complex with Reg1 (Fig. 2D). These results demonstrate the existence of a direct and stable association between Gpa1 and Reg1. Together, these findings support a model in which Reg1-Glc7 acts as a phosphatase for Gpa1.

\section{Whereas mating responses are dampened by Elm1, Sak1, and Tos3, they are promoted by Reg1}

The mating pheromone a-factor stimulates a kinase cascade consisting of Ste11, Ste7, and the MAPK Fus3. To determine whether the basal phosphorylation state of Gpa1 altered its ability to transmit the pheromone signal, we monitored the activation status of Fus 3 by Western blotting analysis with an antibody specific for the dually phosphorylated, fully active form of Fus3 (p-Fus3) (24). As compared to wild-type cells, elm1 $\Delta$ sakl $\Delta$ tos $3 \Delta$ cells were initially more sensitive to pheromone, although they took longer to exhibit full activation of Fus3 (Fig. 3A). In this context, we note that activation of the overall mating pathway is a function of the increased abundance of Fus3 as well as of its increased phosphorylation (25). However, we observed no difference in Fus3 abundance between the wild-type and elm $1 \Delta \operatorname{sakl\Delta tos} 3 \Delta$ strains (Fig. 3A). We inferred from these results that cells were initially more responsive to pheromone if their Gpa1 was unphosphorylated. However, the rapid response to pheromone may also lead to more rapid feedback inhibition, for example, by stimulating production of the GAP Sst2, and this could account for the observed delay in achieving full activation of Fus3. Thus, these data suggest that Elm1, Tos3, and Sak1 are important for suppressing early activation of the matingspecific MAPK in response to a-factor. 
Activation of Fus 3 results in the selective induction of genes whose products are required for proper cell fusion (25). To further assess the contribution of Elm1, Sak1, and Tos3 to the mating response, we measured pathway-specific gene transcription with a reporter construct consisting of the FUS1 promoter fused to the gene encoding $\beta$-galactosidase. Compared to wild-type cells, elm $1 \Delta$ sakl $1 \Delta t o s 3 \Delta$ cells had a nearly twofold increase in maximal pheromone-induced gene transcription (Fig. 3B) and an even greater relative increase under basal conditions.

As a counterpart to the Snf1-activating kinases, we examined the role of the Glc7-Reg1 phosphatase in the mating response. We used a regl $1 \Delta$ mutant strain as well as a strain expressing the Glc7-binding deficient mutant, $\operatorname{Reg} 1^{\mathrm{F} 468 \mathrm{R}}$ (26). Whereas phosphorylation of Fus3 occurred $\sim 30$ min after treatment with pheromone in wild-type cells, peak

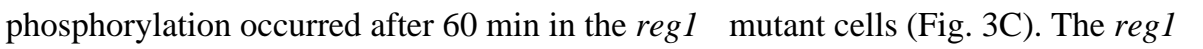
mutant cells also exhibited a $40 \%$ decrease in pheromone-induced gene expression compared to that in wild-type cells (Fig. 3D). Normal signaling was restored in cells transformed with plasmid expressing wild-type Reg1, but not the Reg $1^{\mathrm{F} 468 \mathrm{R}}$ mutant (fig. S2A). Because elm $1 \Delta s a k 1 \Delta t o s 3 \Delta$ cells lacked the ability to appropriately activate Snf1, we also examined the response of $\operatorname{snf} 1 \Delta$ cells to pheromone. Whereas the elm $1 \Delta \operatorname{sak} 1 \Delta t o s 3 \Delta$ cells exhibited an increased response to pheromone compared to that of wild-type cells, the snfl $1 \Delta$ mutant cells produced a somewhat dampened response (fig. S2, B and C). Given these opposing effects on the response to pheromone, we conclude that the Snf1-activating kinases, but not Snf1 itself, serve as inhibitors of the mating response pathway. Conversely, the regulatory subunit of the phosphatase that acts on Snf1 (as well as Snf1) serves as an enhancer of the pathway.

\section{Limited glucose availability dampens the mating response pathway}

Our earlier findings revealed that Gpa1 was dynamically modified by phosphorylation, which occurred under conditions of low glucose concentration, and that the kinases and phosphatase that acted on Snf1 also acted on Gpa1. The Snf1 complex and its human counterparts, the AMPKs, serve as molecular switches to turn on catabolic pathways while suppressing anabolic pathways when cells are under energy-poor or other stressful conditions (27). In light of these findings, we postulated that Gpa1 might serve as a point of crosstalk to delay mating during periods of glucose limitation. To test this model, we investigated how a decrease in extracellular glucose concentration might alter MAPK activation and mating-specific gene expression, as well as the consequent changes in cell morphology and mating efficiency.

We first monitored the activation of Fus3, and we observed a dampened response to pheromone when the glucose concentration was limiting (Fig. 4A). We then conducted the same experiment in cells lacking Elm1, Sak1, and Tos3. Under these conditions, there was no effect of limiting glucose on the activation of Fus3 (Fig. 4B). We also examined Reg1deficient cells, and we observed a marked decrease in p-Fus3 abundance under glucoselimiting conditions, particularly at later time points (Fig. 4C). These changes in the extent of MAPK activation were mirrored in the transcriptional reporter assay, with the exception of the reg $1 \Delta$ mutant cells cultured in low glucose (Fig. 4D). This difference suggests that Reg1 
influences events both upstream and downstream of the MAPKs. Together, these data suggest that the Snf1-activating kinases serve to inhibit the mating pathway.

Whereas phosphorylation of Gpa1 appeared to dampen signaling immediately after stimulation of cells with pheromone, signaling was not dampened when the G protein was bypassed entirely through a constitutively active mutant MAPK kinase kinase (MAPKKK), Ste11 (Fig. 4E) (28). Rather, pathway activity was enhanced under these circumstances, which suggests the existence of an opposing regulatory process late in the pathway. Yet another layer of regulation could occur at the level of gene transcription. As noted earlier, Fus3 activity is a function of an increase in the abundance of Fus3 protein as well as an increase in its phosphorylation status, which suggests that there is a kinase-dependent positive feedback loop that controls the production of Fus3. Indeed, we observed decreased Fus3 protein abundance in both $r e g 1 \Delta$ and wild-type strains of yeast grown under conditions of limited glucose availability (Fig. 4, A and C). Persistent suppression of FUS3 expression could account for the fact that, of all the strains tested, the reg $1 \Delta$ mutant cells showed the greatest glucose-dependent change in Fus3 phosphorylation status (Fig. 4C), but the smallest glucose-dependent change in Gpa1 phosphorylation (Fig. 1A).

Ultimately, a stress-dependent reduction of pheromone responses should lead to impaired mating. Mating in yeast is most efficient when glucose is abundant (29), although, to the best of our knowledge, these effects have never been quantified or characterized by microscopy. In our analysis, we observed a nearly threefold reduction in mating efficiency in cells grown in $0.05 \%$ glucose compared to that in cells grown in $2 \%$ glucose (Fig. $5 \mathrm{~A}$ ). We then monitored pheromone-induced morphological changes in cells, including polarized cell expansion ("shmoo" formation), which produces the eventual site of haploid cell fusion (30). The use of a microfluidic chamber enabled us to maintain fixed concentrations of glucose and pheromone over time. For cells cultured in medium containing $2 \%$ glucose, the addition of a-factor pheromone resulted in shmoo formation after $\sim 120 \mathrm{~min}$. For cells cultured in medium containing $0.05 \%$ glucose, the addition of a-factor resulted in shmoo formation after $180 \mathrm{~min}$ (Fig. 5B). Moreover, whereas pheromone-treated cells normally arrest in the first $\mathrm{G}_{1}$ phase, we found that cells grown in $0.05 \%$ glucose divided once and did not arrest until the second $\mathrm{G}_{1}$ phase (Fig. 5, B and C). In contrast, we observed no differences in the rate of cell division (budding) when pheromone was absent (Fig. 5D). These observations suggest that general cellular and cell cycle functions are not substantially dysregulated under conditions of low glucose concentration, at least for the first 4 hours. We conclude that suppression of the mating pathway and delayed morphogenesis are sufficient to reduce mating efficiency when glucose is limiting. Thus, the same processes that control the metabolic regulator Snf1 also limit the pheromone signaling pathway.

\section{DISCUSSION}

G proteins and GPCRs have long been known to regulate glucose metabolism. Classical studies, performed over the past half century, have revealed how glucagon and other hormones modulate glucose storage and synthesis (31). Here, we demonstrated that crosspathway regulation can also occur in the opposite direction, wherein glucose availability regulates a G protein signaling pathway. Specifically, we showed that the G protein Gpa1 
was phosphorylated in direct response to limited glucose availability. When Gpa1 was phosphorylated, pheromone responses were abrogated. Furthermore, the kinases and phosphatase that act on Gpa1 are the same as those that act on the glucose-sensing substrate Snf1.

Some important questions remain. For example, although phosphorylation of $\mathrm{Ser}^{200}$ is responsible for the shift in Gpa1 mobility when analyzed by SDS-PAGE, there are many other phosphorylation sites that have not yet been mapped or functionally characterized. Moreover, it is not clear how phosphorylation and dephosphorylation events are regulated. Even for the prototype AMPK, Snf1, the mechanism of activation has remained unsolved for many years (32). Current evidence indicates that Snf1-activating kinases are always active (33) but that the activity of the Glc7-Reg1 phosphatase is glucose-regulated $(20,34,35)$. Upon binding to adenosine $5^{\prime}$-diphosphate, which is most abundant in cells grown under conditions of low glucose availability, the Snf 1 complex undergoes a conformational change (32). Consequently, Snf1 is no longer dephosphorylated, and it persists in an activated phosphorylated state until the abundances of glucose and adenosine $5^{\prime}$-triphosphate (ATP) are restored. As long as it remains phosphorylated, Snf1 promotes the transcription of metabolic genes to maintain energy homeostasis (12-14). By analogy with Snf1, it is possible that Gpa1 is constitutively phosphorylated but fails to become dephosphorylated under low-glucose conditions. Gpa1 does not bind to adenosine nucleotides, however, so another ligand may direct conformational change. So far, we have determined that the phosphorylation of Gpa1 is not contingent on its sustained binding to GTP or GDP (fig. S1). Thus, another glucose-mediated change may alter the conformation of the G protein, the phosphatase, or the protein kinases. For example, cytoplasmic $\mathrm{pH}$ drops rapidly in response to low glucose, and these changes could produce conformational changes in Gpa1 that lead to increased phosphorylation (36). We also believe that additional pheromone pathway components are regulated by the glucose-sensing pathway. This is based on the finding that glucose limitation has a strong effect on pheromone signaling in the regl $\Delta$ mutant, despite these cells exhibiting modest changes in the extent of Gpal phosphorylation. Moreover, at least some of the effects of glucose limitation can be attributed to reduced Fus3 abundance, and hence may reflect changes in gene expression as well as G protein activity.

Yeast has long served as a model for investigating fundamental mechanisms of cell signaling and regulation. Our analysis has revealed the glucose-dependent regulation of a $\mathrm{G}$ protein a subunit and a $\mathrm{G}$ protein-mediated signaling pathway. Analysis of both pathways is critical for understanding human health and disease because they are implicated in numerous physiological responses and are important targets of pharmaceuticals $(37,38)$. Examples include metformin (which activates AMPK) and glucagon (a GPCR agonist), which are used for the treatment of type 2 diabetes and hypoglycemia, respectively. Dynamic phosphorylation of a $\mathrm{G}$ protein a subunit, in response to diminished glucose availability, represents a striking example of crosstalk between two critically important signaling systems. More broadly, these findings demonstrate a degree of coordination that serves to prioritize signaling events during conditions of metabolic stress. Given the conservation of G protein and AMPK signaling pathways across species, our findings may lead to similar mechanisms of signal coordination being discovered in humans. 


\section{MATERIALS AND METHODS}

\section{Strains and plasmids}

Standard methods for the growth, maintenance, and transformation of yeast and bacteria were used throughout this work. Strains used in this study were BY4741 (MATa leu2 $\Delta$ met $15 \Delta$ his $3 \Delta$ ura $3 \Delta$ ) and BY4741-derived mutants that were constructed with the KanMX4 G418 resistance marker (Yeast Deletion Clones, Invitrogen; originally purchased from Research Genetics). The snfl $1 \Delta$ strain (BY4741 snfl $1 \Delta:$ KanMX4) that was obtained from Research Genetics did not produce a consistent phenotype, so we regenerated the strain by polymerase chain reaction (PCR)-based amplification of the KanMX4 cassette and transformation of the parent strain (39). Double gene deletion and triple gene deletion strains were generated with PCR-mediated gene disruption cassettes from the pRS400 series of vectors (40). The plasmid pRS313-SAK1 was constructed by PCR amplification of SAK1 \pm $500 \mathrm{bp}$ flanking the opening reading frame (ORF) with the primers SacII-SAK1-F and SmaI-SAK1-R and directional cloning into the Sac II and Sma I sites of pRS313. The plasmid pRS316-REG1 was constructed by the method described earlier with the primers XhoI-REG1-F and KpnI-REG1-R and by cloning into pRS316. The single point mutation of Reg1 ${ }^{\mathrm{F} 468 \mathrm{R}}$ was constructed by QuikChange (Stratagene) mutagenesis with the primer REG1-F468R-F and its complement. The plasmid pAD4M-GPA1-FLAG was constructed by amplifying the GPA1-FLAG ${ }^{\text {Internal }}$ ORF from pRS316-ADH-GPA1-FLAG (7) with the primers SmaI-ADH1-F and SacI-GPA1-R and by cloning into pAD4M. The plasmid pRS316-ADH1-REG1-HA was constructed by QuikChange to substitute an HA tag for the FLAG tag from pRS316-ADH1-REG1-FLAG with the primer REG1-HA-F and its complement. The plasmid for bacterial expression of the $6 \times$ His-MBP Reg 1 fusion protein was generated by ligation-independent cloning, as described previously (41). The sequence encoding REG1 was amplified by PCR from genomic DNA with the primers REG1-MBP-F and REG1-MBP-R and annealed to the gapped $6 \times$ His vector pLIC-MBP (from J. Sondek, University of North Carolina). Details of the strains (table S1), plasmids (table S2), and primers (table S3) used in this study can be found in the Supplementary Materials.

\section{Growth of cultures}

Cells were grown in YPD or SCD medium containing 2\% (w/v) D-glucose. Low-glucose treatment was achieved by growing cells in $2 \%$ glucose medium until they reached the early $\log$ phase, and then cells were centrifuged and washed with $0.05 \%$ glucose medium before being resuspended in $0.05 \%$ glucose medium for $5 \mathrm{~min}$. Cells were then collected for Western blotting analysis or were further treated with the pheromone a-factor.

\section{Protein detection}

Unless otherwise noted, cell pellets were harvested by the addition of $100 \%$ trichloroacetic acid (TCA) to cells in culture medium (to a final concentration of 5\%), centrifuged at $3000 \mathrm{~g}$ for $2 \mathrm{~min}$, washed with $1 \mathrm{ml}$ of $10 \mathrm{mM} \mathrm{NaN}_{3}$, and stored as a frozen cell pellet at $-20^{\circ} \mathrm{C}$. Protein extracts were generated by glass bead lysis in TCA, as described previously (42), and 35- $\mu \mathrm{g}$ aliquots of total cell lysates were resolved by $10 \%$ SDS-PAGE and transferred onto membranes. Western blotting analysis of the membranes was performed with the following antibodies: anti-Gpa1 at 1:1000 dilution (43), anti-FLAG at 1:1000 (F1804, 
Sigma-Aldrich), anti-p44/42 at 1:500 (9101L, Cell Signaling Technology), anti-G6PDH at 1:50,000 (A9521, Sigma-Aldrich), anti-HA at 1:10,000 (A190-108A, Bethyl), antiphospho-AMPKa at 1:2000 (4188, Cell Signaling), anti-Fus3 at 1:500 (sc-6773, Santa Cruz Biotechnology), anti-protein A at 1:50,000 (P3775, Sigma-Aldrich), and anti-MBP at 1:2000 (sc-13914, Santa Cruz Biotechnology). Immunoreactive bands were visualized by chemiluminescence detection (PerkinElmer Life Sciences) of horseradish peroxidase (HRP)-conjugated anti-rabbit immunoglobulin $\mathrm{G}(\operatorname{IgG})$ (1:10,000 dilution, 170-5046) or HRP-conjugated anti-mouse IgG (1:10,000 dilution, 170-5047, Bio-Rad). Blots were exposed to HyBlot CL autoradiography film (Denville Scientific), and densitometric analysis of bands was performed with ImageJ software [National Institutes of Health (NIH)].

\section{Immunoprecipitation of Gpa1-FLAG}

Wild-type cells were transformed with the plasmid pAD4M-GPA1-FLAG or empty vector together with either pRS316-ADH1-REG1-HA and empty vector or pRS426-SAK1-TAP and empty vector. The production and purification of FLAG-tagged proteins were performed as described previously (44). Samples were resolved by 10\% SDS-PAGE and analyzed by Western blotting to detect FLAG- or HA-tagged proteins or TAP fusion proteins.

\section{Purification of TAP and $6 \times$ His fusion proteins}

The TAP tag consists of a calmodulin-binding peptide and two IgG-binding domains of Staphylococcus aureus protein A. We transformed sakl 1 snfl $1 \Delta$ cells with the plasmid pRS426-SAK1-TAP or pRS426-SAK1 ${ }^{\text {D277A }-T A P . ~ T w o-l i t e r ~ c u l t u r e s ~ w e r e ~ g r o w n ~ t o ~ e a r l y ~}$ log phase, and cells were harvested by centrifugation, washed with distilled water, and stored at $-20^{\circ} \mathrm{C}$. The cell pellets were lysed by glass bead agitation in lysis buffer containing $41.7 \mathrm{mM} \mathrm{Na}_{2} \mathrm{HPO}_{4}, 8.3 \mathrm{mM} \mathrm{NaH}_{2} \mathrm{PO}_{4}$ (pH 7.5), $400 \mathrm{mM} \mathrm{NaCl}, 10 \%$ glycerol, $0.1 \%$ Triton X-100 (Sigma-Aldrich), $25 \mathrm{mM} \mathrm{NaF,} 2 \mathrm{mM} \beta$-glycerophosphate, $1 \mathrm{mM}$ dithiothreitol (DTT), $1 \times$ protease inhibitor mixture tablets (Roche), and $500 \mu \mathrm{M}$ phenylmethylsulfonyl fluoride. Samples were rocked for $60 \mathrm{~min}$ to solubilize the proteins. The lysate mixture was subjected to micro-centrifugation at $21,000 \mathrm{~g}$ for $10 \mathrm{~min}$, and $\mathrm{CaCl}_{2}$ at a final concentration of $1 \mathrm{mM}$ was added to the soluble extract to enable the binding of TAP-tagged proteins to 50 $\mu \mathrm{l}$ of calmodulin affinity resin (Agilent) for 2 hours with gentle rocking. The resin was washed five times in $1 \mathrm{ml}$ of lysis buffer containing $1 \mathrm{mM} \mathrm{CaCl}_{2}$ and then eluted with $100 \mu \mathrm{l}$ of lysis buffer containing 2 mM EGTA. Eluted protein was dialyzed with a Slide-A-Lyzer MINI cartridge (Pierce) into dialysis buffer containing $20 \mathrm{mM}$ tris- $\mathrm{HCl}$ (pH 8.0), $100 \mathrm{mM}$ $\mathrm{NaCl}, 2 \mathrm{mM} \mathrm{MgCl} 2$, and $5 \%$ glycerol. About 1 to $5 \mu \mathrm{g}$ of protein were recovered in a typical TAP purification. Recombinant $6 \times$ His-Gpa 1 and $6 \times$ His-MBP-Reg 1 were expressed by autoinduction (45) and purified by nickel-affinity chromatography, as described previously (46), but without cleavage of the $\mathrm{N}$-terminal $6 \times$ His tag.

\section{In vitro kinase assays}

In vitro kinase assays were performed by incubating 0.075 to $0.15 \mathrm{pmol}$ of purified TAP kinase (corresponding to a final concentration of 3 to $6 \mathrm{nM}$ ) and $12.5 \mathrm{pmol}$ of recombinant Gpa1 $(0.5 \mu \mathrm{M}$ final concentration) in $1 \times$ kinase reaction buffer, as described previously for 
Elm1 (6). Reactions were stopped by the addition of $6 \times$ SDS-PAGE loading buffer, and samples were immediately subjected to $10 \%$ SDS-PAGE. Gels were dehydrated and exposed to autoradiography film (HyBlot CL, Denville Scientific).

\section{Steric exclusion chromatography of Gpa1 and Reg1}

Purified 6xHis-Gpa1 and Reg1-MBP proteins were subjected to steric exclusion chromatography with an Akta FPLC system and a Sephacryl 26/60 S200 column (GE Healthcare). One nanomole of $6 \times$ His-Gpa1 and $3.25 \mathrm{nmol}$ of Reg1-MBP were equilibrated in $20 \mathrm{mM}$ tris- $\mathrm{HCl}$ (pH 8.0), $100 \mathrm{mM} \mathrm{NaCl}, 5 \%$ glycerol, $1 \mathrm{mM} \mathrm{DTT}, 2 \mathrm{mM} \mathrm{MgCl}_{2}$, and 20 $\mu \mathrm{M}$ GDP. Proteins were separated at a rate of $0.5 \mathrm{ml} / \mathrm{min}$ and were collected in $7-\mathrm{ml}$ fractions. A 20- $\mu \mathrm{l}$ sample from each fraction was resolved by SDS-PAGE and analyzed by Western blotting with anti-Gpa1 or anti-MBP antibodies.

\section{Pheromone transcriptional reporter assay and quantitative mating assay}

Transcriptional reporter assays (47) and mating assays (48) were performed as described previously. For the mating assay, equal amounts of early-log phase MATa cells (BY4741) and MATa cells (BY4742, leu2 $\Delta$ his $3 \Delta$ ura3 $\Delta$ lys $2 \Delta M E T^{+}$) were mixed, filtered onto nitrocellulose membranes, and incubated on YPD plates containing 2 or $0.05 \%$ glucose. After 4 hours of incubation, cells were resuspended and plated onto SCD or SD (synthetic medium containing dextrose) and only Leu/His/Ura. Mating efficiency was calculated by dividing the number of diploid colonies by the total number of cells on an SCD plate.

\section{Microscopy}

A microfluidic device was constructed similar to one previously described (49). Cells were imaged every $5 \mathrm{~min}$ for 12 hours. Image acquisition was performed with an Olympus spinning disc confocal microscope, and image processing and analysis were performed with ImageJ software.

\section{Statistical analysis}

To assess statistical significance, we used Student's $t$ test for pairwise comparisons. $P<0.05$ was considered statistically significant. Error bars represent the means \pm SEM of replicates within individual experiments.

\section{Supplementary Material}

Refer to Web version on PubMed Central for supplementary material.

\section{Acknowledgments}

We thank M. Carlson and M. Torres for their advice and encouragement, M. Schmidt for the Sak1 plasmid used for in vitro kinase assays, M. Lee for his early contributions to the analysis of Reg1, and H. Lien for performing the mating efficiency assays.

Funding: This work was supported by NIH grant GM059167 to H.G.D. 


\section{REFERENCES AND NOTES}

1. Gutkind JS. Regulation of mitogen-activated protein kinase signaling networks by G proteincoupled receptors. Sci. STKE. 2000; 2000 re1.

2. Sherwood NM, Krueckl SL, McRory JE. The origin and function of the pituitary adenylate cyclaseactivating polypeptide (PACAP)/glucagon superfamily. Endocr. Rev. 2000; 21:619-670. [PubMed: 11133067]

3. Dohlman HG, Thorner JW. Regulation of G protein-initiated signal transduction in yeast: Paradigms and principles. Annu. Rev. Biochem. 2001; 70:703-754. [PubMed: 11395421]

4. Stone DE, Cole GM, de Barros Lopes M, Goebl M, Reed SI. $N$-myristoylation is required for function of the pheromone-responsive $G_{a}$ protein of yeast: Conditional activation of the pheromone response by a temperature-sensitive $N$-myristoyl transferase. Genes Dev. 1991; 5:1969-1981. [PubMed: 1936988]

5. Song J, Dohlman HG. Partial constitutive activation of pheromone responses by a palmitoylationsite mutant of a G protein a subunit in yeast. Biochemistry. 1996; 35:14806-14817. [PubMed: 8942643]

6. Torres MP, Clement ST, Cappell SD, Dohlman HG. Cell cycle-dependent phosphorylation and ubiquitination of a G protein a subunit. J. Biol. Chem. 2011; 286:20208-20216. [PubMed: 21521692]

7. Cappell SD, Baker R, Skowyra D, Dohlman HG. Systematic analysis of essential genes reveals important regulators of G protein signaling. Mol. Cell. 2010; 38:746-757. [PubMed: 20542006]

8. Sreenivasan A, Kellogg D. The Elm1 kinase functions in a mitotic signaling network in budding yeast. Mol. Cell. Biol. 1999; 19:7983-7994. [PubMed: 10567524]

9. Sutherland CM, Hawley SA, McCartney RR, Leech A, Stark MJ, Schmidt MC, Hardie DG. Elm1p is one of the three upstream kinases for the Saccharomyces cerevisiae SNF1 complex. Curr. Biol. 2003; 13:1299-1305. [PubMed: 12906789]

10. Carlson M, Osmond BC, Botstein D. Mutants of yeast defective in sucrose utilization. Genetics. 1981; 98:25-40. [PubMed: 7040163]

11. McCartney RR, Schmidt MC. Regulation of the Snf1 kinase. Activation requires phosphorylation of threonine 210 by an upstream kinase as well as a distinct step mediated by the Snf4 subunit. J. Biol. Chem. 2001; 276:36460-36466. [PubMed: 11486005]

12. Hardie DG, Carling D, Carlson M. The AMP-activated/Snf1 protein kinase subfamily: Metabolic sensors of the eukaryotic cell. Annu. Rev. Biochem. 1998; 67:821-855. [PubMed: 9759505]

13. Young ET, Dombek KM, Tachibana C, Ideker T. Multiple pathways are coregulated by the protein kinase Snf1 and the transcription factors Adr1 and Cat8. J. Biol. Chem. 2003; 278:26146-26158. [PubMed: 12676948]

14. Hedbacker K, Carlson M. SNF1/AMPK pathways in yeast. Front. Biosci. 2008; 13:2408-2420. [PubMed: 17981722]

15. Hong SP, Leiper FC, Woods A, Carling D, Carlson M. Activation of yeast Snf1 and mammalian AMP-activated protein kinase by upstream kinases. Proc. Natl. Acad. Sci. U.S.A. 2003; 100:88398843. [PubMed: 12847291]

16. Woods A, Munday MR, Scott J, Yang X, Carlson M, Carling D. Yeast SNF1 is functionally related to mammalian AMP-activated protein kinase and regulates acetyl-CoA carboxylase in vivo. J. Biol. Chem. 1994; 269:19509-19515. [PubMed: 7913470]

17. Hedbacker K, Hong SP, Carlson M. Pak1 protein kinase regulates activation and nuclear localization of Snf1-Gal83 protein kinase. Mol. Cell. Biol. 2004; 24:8255-8263. [PubMed: 15340085]

18. Ludin K, Jiang R, Carlson M. Glucose-regulated interaction of a regulatory subunit of protein phosphatase 1 with the $\mathrm{Snf} 1$ protein kinase in Saccharomyces cerevisiae. Proc. Natl. Acad. Sci. U.S.A. 1998; 95:6245-6250. [PubMed: 9600950]

19. Tu J, Carlson M. REG1 binds to protein phosphatase type 1 and regulates glucose repression in Saccharomyces cerevisiae. EMBO J. 1995; 14:5939-5946. [PubMed: 8846786] 
20. Ruiz A, Liu Y, Xu X, Carlson M. Heterotrimer-independent regulation of the activation-loop phosphorylation of Snf1 protein kinase involves two protein phosphatases. Proc. Natl. Acad. Sci. U.S.A. 2012; 109:8652-8657. [PubMed: 22589305]

21. Blumer KJ, Thorner J. $\beta$ and $\gamma$ subunits of a yeast guanine nucleotide-binding protein are not essential for membrane association of the a subunit but are required for receptor coupling. Proc. Natl. Acad. Sci. U.S.A. 1990; 87:4363-4367. [PubMed: 2161538]

22. Dohlman HG, Apaniesk D, Chen Y, Song J, Nusskern D. Inhibition of G-protein signaling by dominant gain-of-function mutation in Sst2p, a pheromone desensitization factor in Saccharomyces cerevisiae . Mol. Cell. Biol. 1995; 15:3635-3643. [PubMed: 7791771]

23. Slessareva JE, Routt SM, Temple B, Bankaitis VA, Dohlman HG. Activation of the phosphatidylinositol 3-kinase Vps34 by a G protein a subunit at the endosome. Cell. 2006; 126:191-203. [PubMed: 16839886]

24. Sabbagh W Jr, Flatauer LJ, Bardwell AJ, Bardwell L. Specificity of MAP kinase signaling in yeast differentiation involves transient versus sustained MAPK activation. Mol. Cell. 2001; 8:683-691. [PubMed: 11583629]

25. Roberts CJ, Nelson B, Marton MJ, Stoughton R, Meyer MR, Bennett HA, He YD, Dai H, Walker WL, Hughes TR, Tyers M, Boone C, Friend SH. Signaling and circuitry of multiple MAPK pathways revealed by a matrix of global gene expression profiles. Science. $2000 ; 287: 873-880$. [PubMed: 10657304]

26. Sanz P, Alms GR, Haystead TA, Carlson M. Regulatory interactions between the Reg1-Glc7 protein phosphatase and Snf1 protein kinase. Mol. Cell. Biol. 2000; 20:1321-1328. [PubMed: 10648618]

27. Hardie DG, Ross FA, Hawley SA. AMPK: A nutrient and energy sensor that maintains energy homeostasis. Nat. Rev. Mol. Cell Biol. 2012; 13:251-262. [PubMed: 22436748]

28. Stevenson BJ, Rhodes N, Errede B, Sprague FG Jr. Constitutive mutants of the protein kinase STE11 activate the yeast pheromone response pathway in the absence of G protein. Genes Dev. 1992; 6:1293-1304. [PubMed: 1628832]

29. Shimoda C, Yanagishima N. Mating reaction in Saccharomyces cerevisiae VI. Effect of 2deoxyglucose on conjugation. Plant Cell Physiol. 1974; 15:767-778.

30. Ydenberg CA, Rose MD. Yeast mating: A model system for studying cell and nuclear fusion. Methods Mol. Biol. 2008; 475:3-20. [PubMed: 18979235]

31. Rall TW, Sutherland EW, Berthet J. The relationship of epinephrine and glucagon to liver phosphorylase. IV. Effect of epinephrine and glucagon on the reactivation of phosphorylase in liver homogenate. J. Biol. Chem. 1957; 224:463-475. [PubMed: 13398422]

32. Mayer FV, Heath R, Underwood E, Sanders MJ, Carmena D, McCartney RR, Leiper FC, Xiao B, Jing C, Walker PA, Haire LF, Ogrodowicz R, Martin SR, Schmidt MC, Gamblin SJ, Carling D. ADP regulates SNF1, the Saccharomyces cerevisiae homolog of AMP-activated protein kinase. Cell Metab. 2011; 14:707-714. [PubMed: 22019086]

33. Rubenstein EM, McCartney RR, Zhang C, Shokat KM, Shirra MK, Arndt KM, Schmidt MC. Access denied: Snf1 activation loop phosphorylation is controlled by availability of the phosphorylated threonine 210 to the PP1 phosphatase. J. Biol. Chem. 2008; 283:222-230. [PubMed: 17991748]

34. Nigavekar SS, Tan YS, Cannon JF. Glc8 is a glucose-repressible activator of Glc7 protein phosphatase-1. Arch. Biochem. Biophys. 2002; 404:71-79. [PubMed: 12127071]

35. Castermans D, Somers I, Kriel J, Louwet W, Wera S, Versele M, Janssens V, Thevelein JM. Glucose-induced posttranslational activation of protein phosphatases PP2A and PP1 in yeast. Cell Res. 2012; 22:1058-1077. [PubMed: 22290422]

36. Isom DG, Sridharan V, Baker R, Clement ST, Smalley DM, Dohlman HG. Protons as second messenger regulators of G protein signaling. Mol. Cell. 2013; 51:531-538. [PubMed: 23954348]

37. Inoki K, Kim J, Guan KL. AMPK and mTOR in cellular energy homeostasis and drug targets. Annu. Rev. Pharmacol. Toxicol. 2012; 52:381-400. [PubMed: 22017684]

38. Shoichet BK, Kobilka BK. Structure-based drug screening for G-protein-coupled receptors. Trends Pharmacol. Sci. 2012; 33:268-272. [PubMed: 22503476] 
39. Janke C, Magiera MM, Rathfelder N, Taxis C, Reber S, Maekawa H, Moreno-Borchart A, Doenges G, Schwob E, Schiebel E, Knop MA. versatile toolbox for PCR-based tagging of yeast genes: New fluorescent proteins, more markers and promoter substitution cassettes. Yeast. 2004; 11:947-962. [PubMed: 15334558]

40. Brachmann CB, Davies A, Cost GJ, Caputo E, Li J, Hieter P, Boeke PD. Designer deletion strains derived from Saccharomyces cerevisiae S288C: A useful set of strains and plasmids for PCRmediated gene disruption and other applications. Yeast. 1998; 14:115-132. [PubMed: 9483801]

41. Stols L, Gu M, Dieckman L, Raffen R, Collart FR, Donnelly MI. A new vector for highthroughput, ligation-independent cloning encoding a tobacco etch virus protease cleavage site. Protein Expr. Purif. 2002; 25:8-15. [PubMed: 12071693]

42. Lee MJ, Dohlman HG. Coactivation of G protein signaling by cell-surface receptors and an intracellular exchange factor. Curr. Biol. 2008; 18:211-215. [PubMed: 18261907]

43. Dohlman HG, Goldsmith P, Spiegel AM, Thorner J. Pheromone action regulates G-protein asubunit myristoylation in yeast Saccharomyces cerevisiae . Proc. Natl. Acad. Sci. U.S.A. 1993; 90:9688-9692. [PubMed: 8415763]

44. Heenan EJ, Vanhooke JL, Temple BR, Betts L, Sondek JE, Dohlman HG. Structure and function of Vps 15 in the endosomal G protein signaling pathway. Biochemistry. 2009; 48:6390-6401. [PubMed: 19445518]

45. Studier FW. Protein production by auto-induction in high density shaking cultures. Protein Expr. Purif. 2005; 41:207-234. [PubMed: 15915565]

46. Torres MP, Lee MJ, Ding F, Purbeck C, Kuhlman B, Dokholyan NV, Dohlman HG. G protein mono-ubiquitination by the Rsp5 ubiquitin ligase. J. Biol. Chem. 2009; 284:8940-8950. [PubMed: 19176477]

47. Hoffman GA, Garrison TR, Dohlman HG. Analysis of RGS proteins in Saccharomyces cerevisiae . Methods Enzymol. 2002; 344:617-631. [PubMed: 11771415]

48. Sprague FG Jr. Assay of yeast mating reaction. Methods Enzymol. 1991; 194:77-93. [PubMed: 2005823]

49. Hao N, Nayak S, Behar M, Shanks RH, Nagiec MJ, Errede B, Hasty J, Elston TC, Dohlman HG. Regulation of cell signaling dynamics by the protein kinase-scaffold Ste5. Mol. Cell. 2008; 30:649-656. [PubMed: 18538663]

50. Ballester R, Marchuk D, Boguski M, Saulino A, Letcher R, Wigler M, Collins F. The NF1 locus encodes a protein functionally related to mammalian GAP and yeast IRA proteins. Cell. 1990; 63:851-859. [PubMed: 2121371]

51. Sikorski RS, Hieter P. A system of shuttle vectors and yeast host strains designed for efficient manipulation of DNA in Saccharomyces cerevisiae . Genetics. 1989; 122:19-27. [PubMed: 2659436]

52. Hoffman GA, Garrison TR, Dohlman HG. Endoproteolytic processing of Sst2, a multidomain regulator of $\mathrm{G}$ protein signaling in yeast. J. Biol. Chem. 2000; 275:37522-37541.

53. Elbing K, McCartney RR, Schmidt MC. Purification and characterization of the three Snf1activating kinases of Saccharomyces cerevisiae . Biochem. J. 2006; 393:797-805. [PubMed: 16201971] 
A

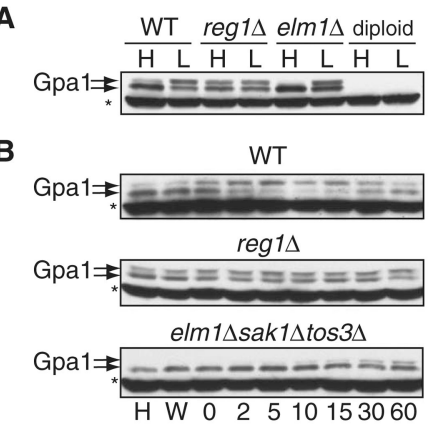

C

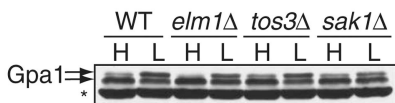

D

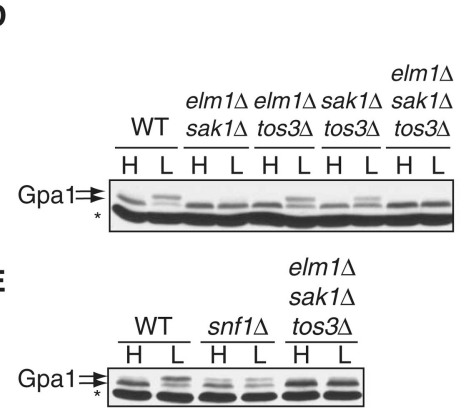

$\mathbf{F}$

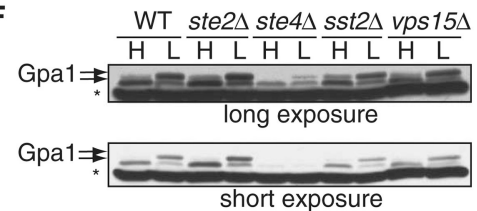

PSAK1 EV G

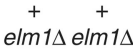
$\operatorname{sak} 1 \Delta \operatorname{sak} 1 \Delta$ tos $3 \Delta$ tos $3 \Delta$ $\overline{\mathrm{HL}} \overline{\mathrm{HL}}$ $=0$

G

\begin{tabular}{|c|c|c|}
\hline Strain & BGn1 (H) & \\
\hline WT & $13.9 \pm 0.9$ & $59.3 \pm 0.2$ \\
\hline reg1A & $38.2 \pm 0.4$ & $41.2 \pm 0.1$ \\
\hline$e / m 1 \Delta$ & $5.3 \pm 0.8$ & $40.4 \pm 0.3$ \\
\hline $\operatorname{tos} 3 \Delta$ & $19.9 \pm 0.8$ & $42.1 \pm 0.3$ \\
\hline sak $1 \Delta$ & $14.6 \pm 0.6$ & $30.4 \pm 0.9$ \\
\hline elm1 $1 \Delta \operatorname{sak} 1 \Delta$ & $6.6 \pm 3.6$ & $10.5 \pm 4.5$ \\
\hline elm1 $1 \Delta t o s 3 \Delta$ & $4.7 \pm 3.1$ & $48.3 \pm 0.1$ \\
\hline sak1 $1 \Delta t o s 3 \Delta$ & $10.8 \pm 4.7$ & $35.7 \pm 1.5$ \\
\hline elm1 $1 \Delta \operatorname{sak} 1 \Delta t o s 3 \Delta$ & $5.1 \pm 0.6$ & $9.2 \pm 1.4$ \\
\hline snf1 $1 \Delta$ & $24.7 \pm 1.4$ & $37.0 \pm 0.7$ \\
\hline ste4a & $47 \pm 20$ & $26.5+0.3$ \\
\hline
\end{tabular}

Fig. 1. Gpa1 is phosphorylated in cells cultured under conditions of low glucose availability (A) Wild-type (WT), regl $1 \Delta$, elm $1 \Delta$, and diploid yeast strains expressing endogenous GPA1 were grown in yeast extract, peptone, and dextrose (YPD) containing $2 \%$ [high $(\mathrm{H})]$ or $0.05 \%$ [low (L)] glucose and were analyzed by Western blotting with an anti-Gpa1 antibody. Treatment with $0.05 \%$ glucose was performed for $5 \mathrm{~min}$ after cells had undergone log-phase growth in YPD containing 2\% glucose. Diploid cells do not have Gpa1 and thus were used as a negative control for the antibody. Gpa1 was detected in two bands indicated by the arrows; the upper band corresponds to the phosphorylated protein. The asterisk denotes a nonspecific band. (B) Time-course analysis of Gpa1 phosphorylation. WT, regl $1 \Delta$, and elml $\Delta$ sakl $\Delta$ tos $3 \Delta$ strains were grown in $2 \%$ glucose $(\mathrm{H})$, were washed in $0.05 \%$ glucose $(\mathrm{W})$, or were grown in $0.05 \%$ glucose for the indicated times (in minutes). Cell lysates were analyzed by Western blotting with an anti-Gpa1 antibody. (C) Analysis of Gpa1 phosphorylation in yeast strains singly deficient in kinases that phosphorylate Snf1. WT cells and the indicated strains were treated as described in (A) and were analyzed by Western blotting with anti-Gpa1 antibody. (D) Left: Analysis of Gpa1 phosphorylation in WT cells and in the indicated double and triple kinase-deficient strains treated as described in (A). Right: Effect of reconstitution of the triple kinase-deficient strain with plasmid encoding Sak1. Yeast cells deficient in Elm1, Sak1, and Tos3 were transformed with empty vector (EV) or with plasmid encoding Sak1, treated as described in (A), and then analyzed by Western blotting with antibody against Gpa1. (E) Comparison of the responses of the $\operatorname{snfl} 1 \Delta$ strain to high and low glucose with those of WT cells and the elml $1 \Delta a k 1 \Delta t o s 3 \Delta$ strain. Cells were treated and analyzed as described in (A). (F) Effect of the loss of Gpa1 signaling components on its phosphorylation. Top: WT cells and the ste $2 \Delta$, ste $4 \Delta$, sst $2 \Delta$, and vps $15 \Delta$ strains were treated and analyzed as described in (A). Bottom: Shorter exposure of the Western blot shown above. (G) Quantitation of the abundances of phosphorylated Gpa1 (pGpa1) protein in the indicated strains exposed to high- or low-glucose conditions as determined by densitometric analysis of bands from three individual experiments. The amount of pGpa1 protein in each strain is expressed as a percentage of the amount of total Gpa1 protein. Western blotting data in (A) to (F) are representative of three independent experiments, except for (B), which is representative of two independent experiments. 


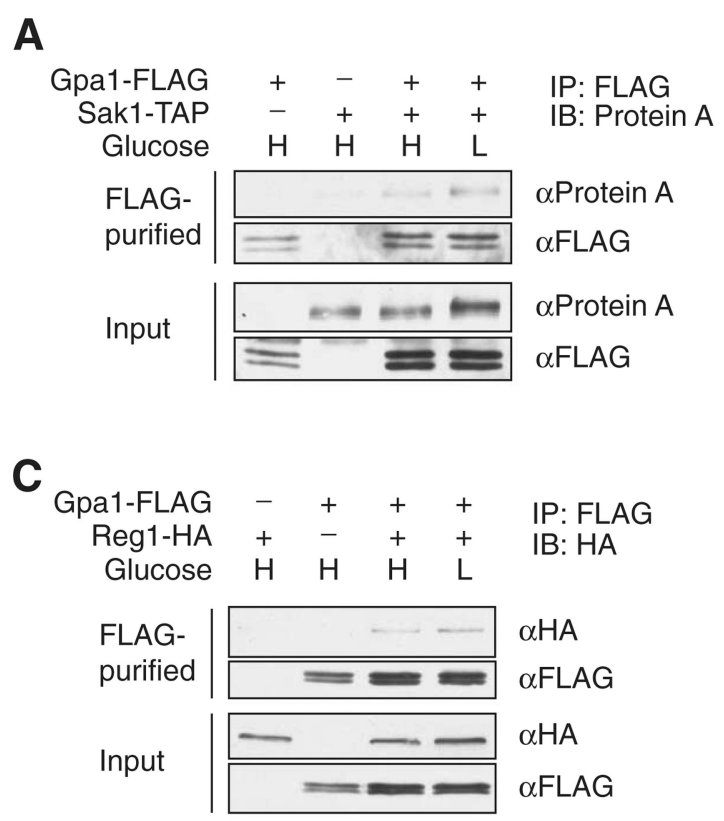

B

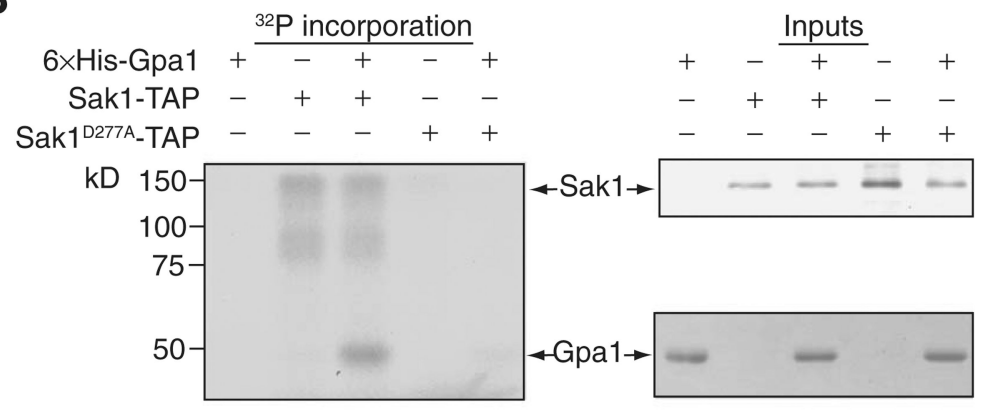

D

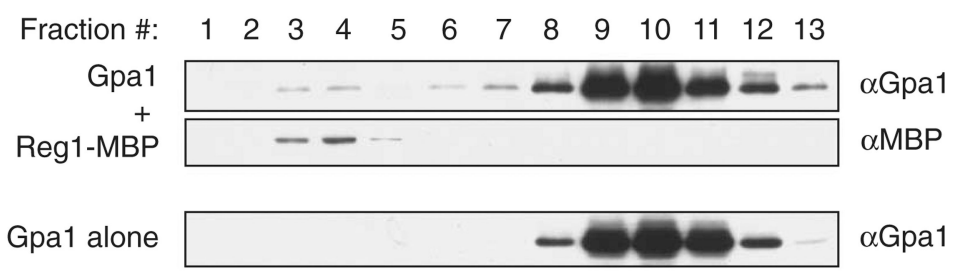

Reg1-MBP alone $\quad-\cdots$ MBP

Fig. 2. The protein kinase Sak1 and the phosphatase regulatory subunit Reg1 act on Gpa1 (A) Coimmunoprecipitation of Gpa1 and Sak1. WT cells were transformed with plasmids encoding the indicated proteins and were cultured under high-glucose $(\mathrm{H})$ or low-glucose (L) conditions. Cells were subjected to immunoprecipitation (IP) with an anti-FLAG antibody (aFLAG), eluted in SDS-PAGE sample buffer, and then analyzed by Western blotting (IB) to detect coimmunoprecipitated Sak1-TAP with antibody against protein A (aProtein A). Cell lysates (input) were also analyzed by Western blotting with the indicated antibodies. (B) In vitro kinase assays. Purified TAP fusion proteins of WT Sak1 (Sak1-TAP) or a kinase-deficient mutant Sak1 (Sak1 ${ }^{\mathrm{D} 277 \mathrm{~A}}$-TAP) were incubated with or without purified recombinant Gpa1 protein in the presence of $\left[\gamma^{32} \mathrm{P}\right]$ ATP. The Sak1-TAP fusion proteins were purified from a sakl $\Delta s n f 1 \Delta$ strain to avoid potential copurification of Snf1. Left: Autoradiogram showing the incorporation of radioactive phosphate into the indicated proteins. Right: The Sak1-TAP input was detected by Western blotting analysis with antibody against protein A, whereas the Gpa1 input was detected by Coomassie gel staining. (C) Coimmunoprecipitation of Reg1 and Gpa1. WT cells were transformed with plasmids encoding the indicated constructs and were cultured under high- or low-glucose conditions. Cell lysates were subjected to immunoprecipitation with anti-FLAG antibody, eluted in SDS-PAGE sample buffer, and then analyzed by Western blotting with an antihemagglutinin (HA) antibody to detect coimmunoprecipitated Reg1-HA. Cell lysates (input) were also analyzed by Western blotting with the indicated antibodies. (D) Purified recombinant $6 \times$ His-Gpa1 and Reg1-MBP (maltose-binding protein) proteins were combined in vitro and resolved by steric exclusion chromatography. Proteins were detected by Western blotting analysis with antibodies specific for Gpa1 or MBP. All data are representative of two independent experiments. 

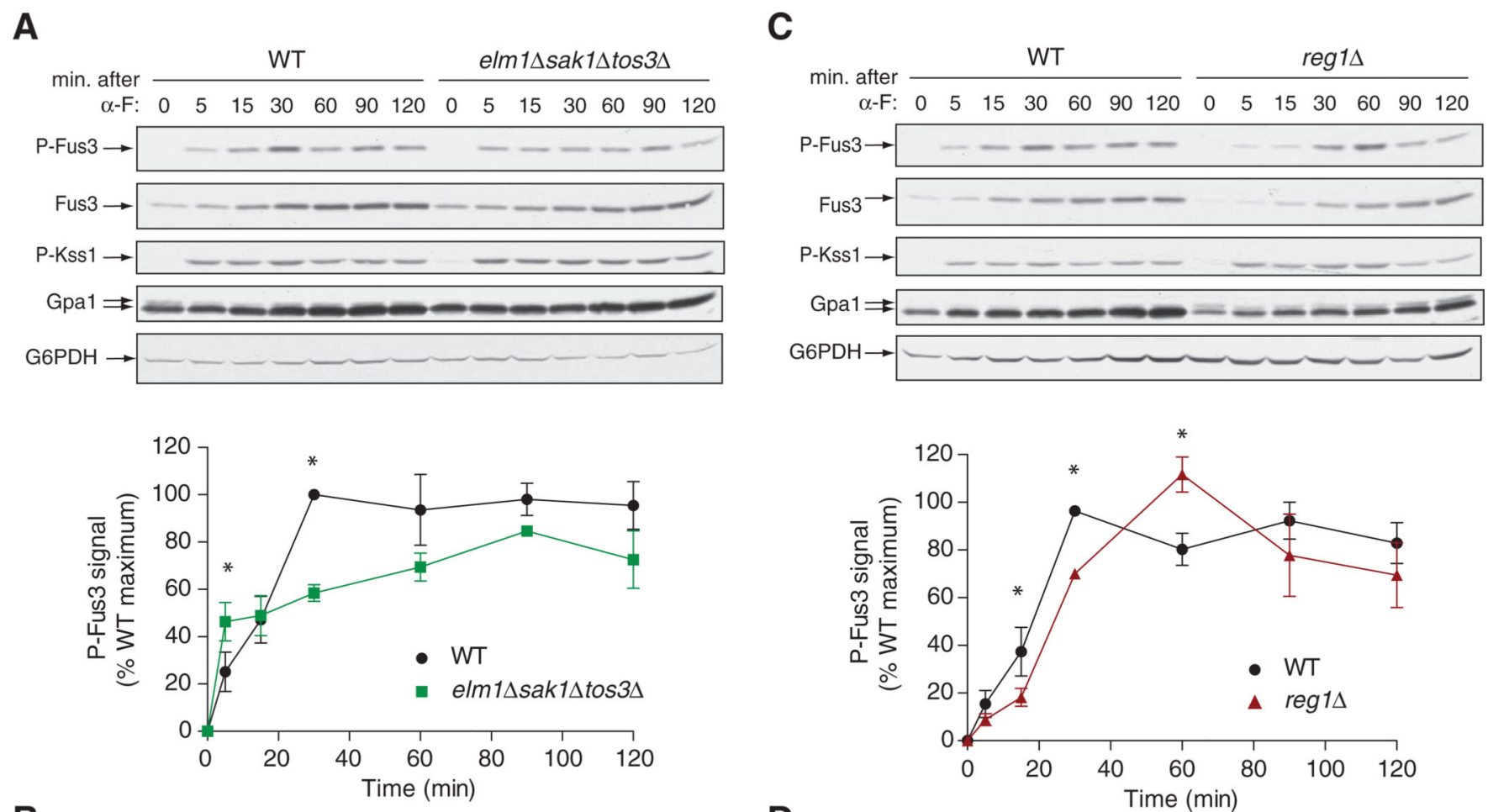

B

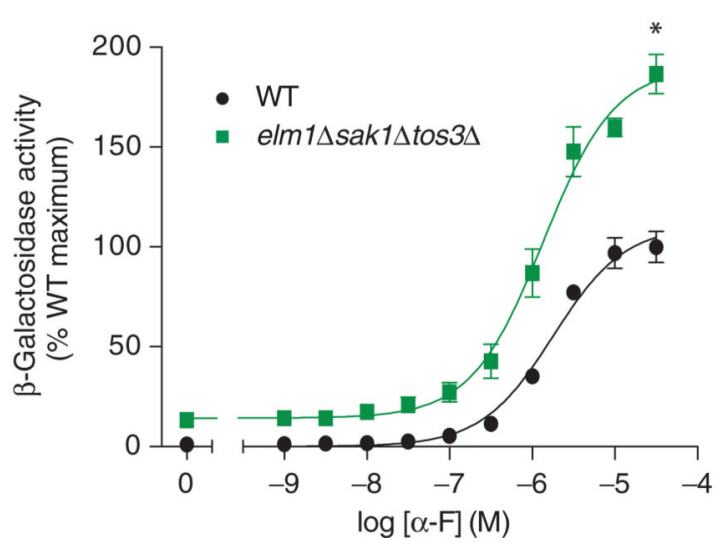

D
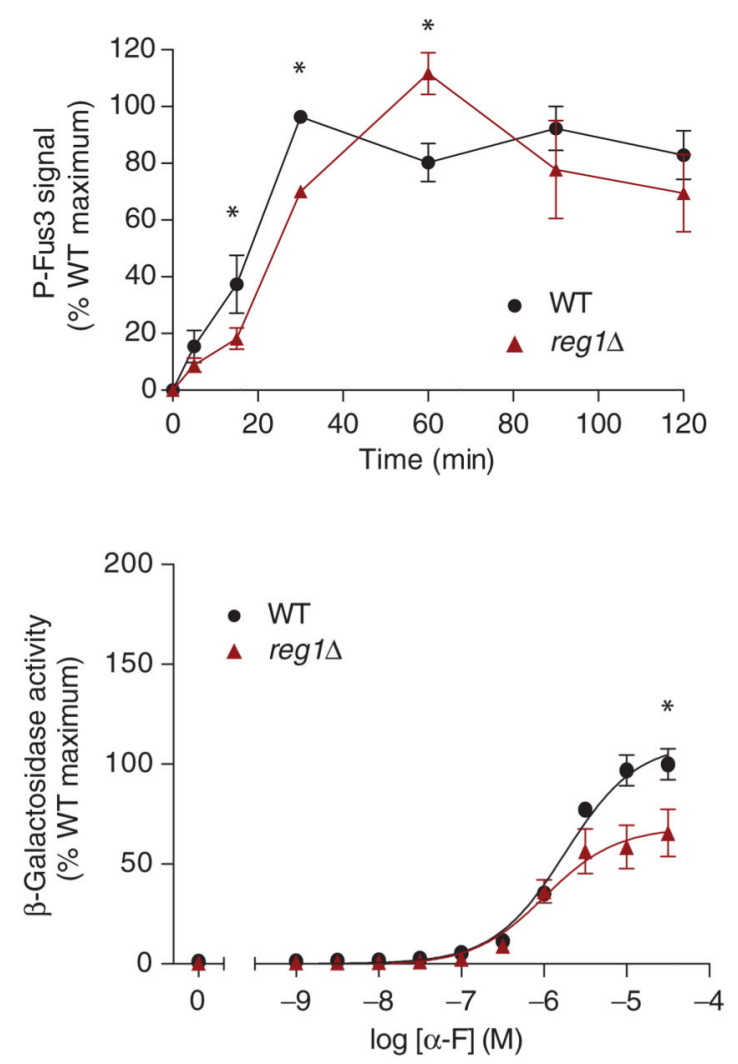

Fig. 3. Snf1-activating kinases limit early mating responses, whereas Reg1 promotes maximal mating responses

(A) Early-log phase cultures of WT and elm1 $\Delta$ sakl 1 tos $3 \Delta$ cells were left untreated or treated with $3 \mu \mathrm{M}$ a-factor ( $\mathrm{a}-\mathrm{F}$ ) for the indicated times before samples were harvested. Top: Western blotting analysis of samples with antibody against phosphorylated p44/42 MAPK (to detect p-Fus3 and p-Kss1), antibody against total Fus3 protein, and antibody against Gpa1. Glucose-6-phosphate dehydrogenase (G6PDH) was used as a loading control.

Bottom: Densitometric analysis of the abundance of p-Fus3 in each sample normalized to the abundance of total Fus3 protein. Data are means \pm SEM from three independent experiments. ${ }^{*} P<0.05$. (B) Analysis of pheromone-dependent gene transcription in WT and elm1 $\Delta$ sak1 $\Delta$ tos $3 \Delta$ cells. Cells expressing a FUS1-lacZ reporter were treated with the indicated concentrations of $\alpha$-factor for $90 \mathrm{~min}$, and then $\beta$-galactosidase activity was measured. Data are means \pm SEM from three experiments, each performed in quadruplicate. 
Data are expressed as a percentage of the $\beta$-galactosidase activity of WT cells at the maximum concentration of pheromone. ${ }^{*} P<0.05$. (C) Early-log phase cultures of WT and regl $\Delta$ cells were left untreated or treated with $3 \mu \mathrm{M}$ a-factor $(\alpha-F)$ for the indicated times before samples were harvested. Top: Western blotting analysis of samples with antibody against phosphorylated p44/42 (to detect p-Fus3 and p-Kss1), antibody against total Fus3 protein, and antibody against Gpa1. G6PDH was used as a loading control. Bottom: Densitometric analysis of the abundance of p-Fus3 in each sample normalized to the abundance of total Fus3 protein. Data are means \pm SEM from three independent experiments. ${ }^{*} P<0.05$. (D) Analysis of pheromone-dependent gene transcription in WT and reg $1 \Delta$ cells. Cells expressing a FUS1-lacZ reporter were treated with the indicated concentrations of a-factor for $90 \mathrm{~min}$, and then $\beta$-galactosidase activity was measured. Data are means \pm SEM from three experiments, each performed in quadruplicate. Data are expressed as a percentage of the $\beta$-galactosidase activity of WT cells at the maximum concentration of pheromone. ${ }^{*} P<0.05$. 


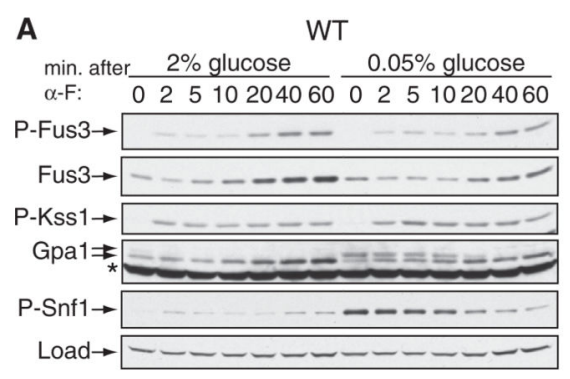

\section{B}

min. after $2 \%$ glucose $\quad 0.05 \%$ glucose

$\alpha-F: \quad 0251020406002510204060$

$P$-Fus $3 \rightarrow \square$

Fus $3 \rightarrow-\infty \ldots \ldots$

P-Kss1 $\rightarrow$

Gpa1 $\Rightarrow$ =-

P-Snf1 $\rightarrow$

Load-
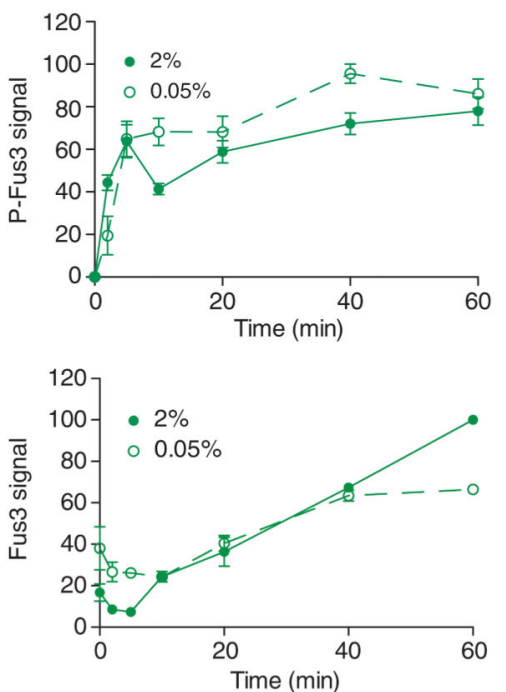

C

min. after $2 \%$ glucose $\quad 0.05 \%$ glucose $\alpha-F: \quad 0251020406002510204060$ $P$-Fus $3 \rightarrow-\ldots-\cdots$

Fus $3 \rightarrow--\cdots---1-\cdots$

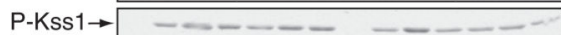

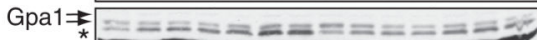

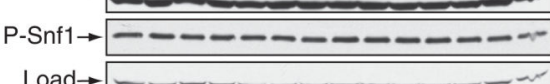

Load $\rightarrow$ -
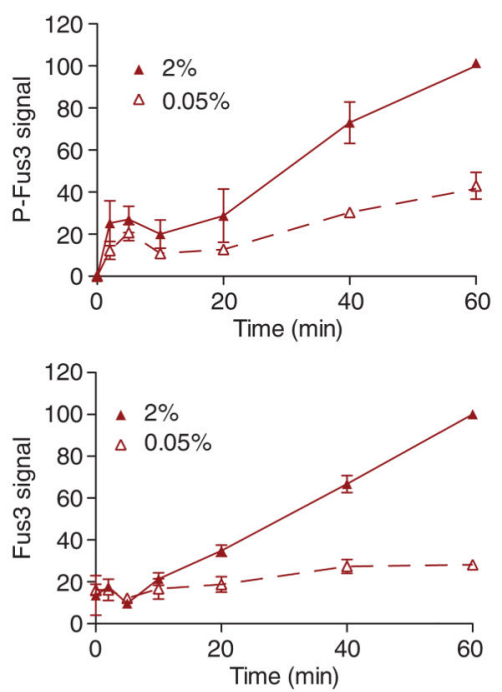

E

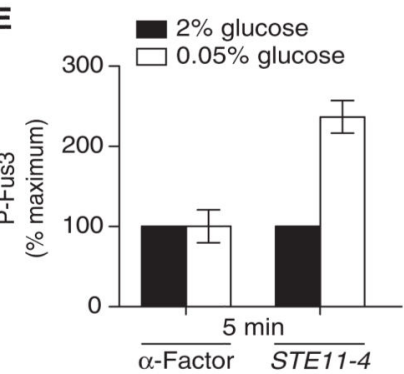

D

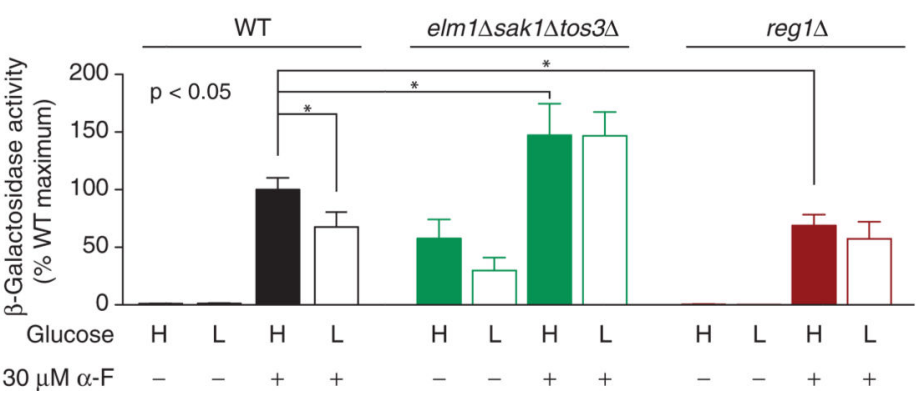

Fig. 4. Crosstalk between mating and glucose-sensing pathways

(A to $\mathbf{C})$ Analysis of the effects of high and low glucose on the abundance and phosphorylation of Fus3. (A) WT cells, (B) elml $\Delta \operatorname{sak} 1 \Delta t o s 3 \Delta$ cells, and (C) reg $1 \Delta$ cells were cultured in medium containing 2 or $0.05 \%$ glucose for $5 \mathrm{~min}$ before being left untreated or treated with $3 \mu \mathrm{M}$ a-factor $(\mathrm{a}-\mathrm{F})$ for the indicated times before they were harvested for analysis. Top: Samples were analyzed by Western blotting with antibody against phosphorylated p44/42 MAPK (to detect p-Fus3 and p-Kss1), as well as with antibodies specific for total Fus3, Gpa1, phosphorylated Snf1 (p-Snf1), and G6PDH, which was used as a loading control. Middle: Densitometric analysis of the abundance of p-Fus3. Bottom: Densitometric analysis of the abundance of total Fus3. For densitometric analysis, the most intense band on each blot was set at $100 \%$, and the intensities of the other bands were expressed as percentages of the maximum. Results are means \pm SEM from three independent experiments. (D) Analysis of pheromone-dependent gene transcription in WT, elml 1 sakl $\Delta$ tos $3 \Delta$, and reg $1 \Delta$ cells expressing a $F U S 1$-lacZ reporter that were left untreated 
or treated with $30 \mu \mathrm{M}$ a-factor for $90 \mathrm{~min}$ in medium containing either 2 or $0.05 \%$ glucose. Data are expressed as percentages of the $\beta$-galactosidase activity of pheromone-treated WT cells cultured in $2 \%$ glucose, which was set at $100 \%$. Data are means \pm SEM from three independent experiments, each performed in quadruplicate. $* P<0.05$. (E) WT cells were transformed with empty plasmid or with plasmid encoding STE11-4, a constitutively active mutant of the MAPKKK Ste11. Early-log phase cells were resuspended in medium containing either 2 or $0.05 \%$ glucose. Cells transformed with empty plasmid were treated with $3 \mu \mathrm{M}$ a-factor for $5 \mathrm{~min}$, whereas cells expressing STE1 1-4 were collected $5 \mathrm{~min}$ after resuspension in fresh medium. Samples were analyzed by Western blotting with antibodies against phosphorylated p44/42 MAPK and total Fus3. Bar graphs represent densitometric analysis of the intensities of bands corresponding to p-Fus3, normalized to those corresponding to total Fus3. For each set of cells, the abundance of p-Fus3 in $2 \%$ glucose was set at $100 \%$. Data are means \pm SEM from three independent experiments. 
A

\begin{tabular}{cc}
\multicolumn{2}{c}{ Quantitative mating } \\
\hline Glucose & Mating efficiency (\%) \\
\hline $2 \%$ & $77 \pm 4$ \\
$0.05 \%$ & $28 \pm 3$ \\
\hline
\end{tabular}

B
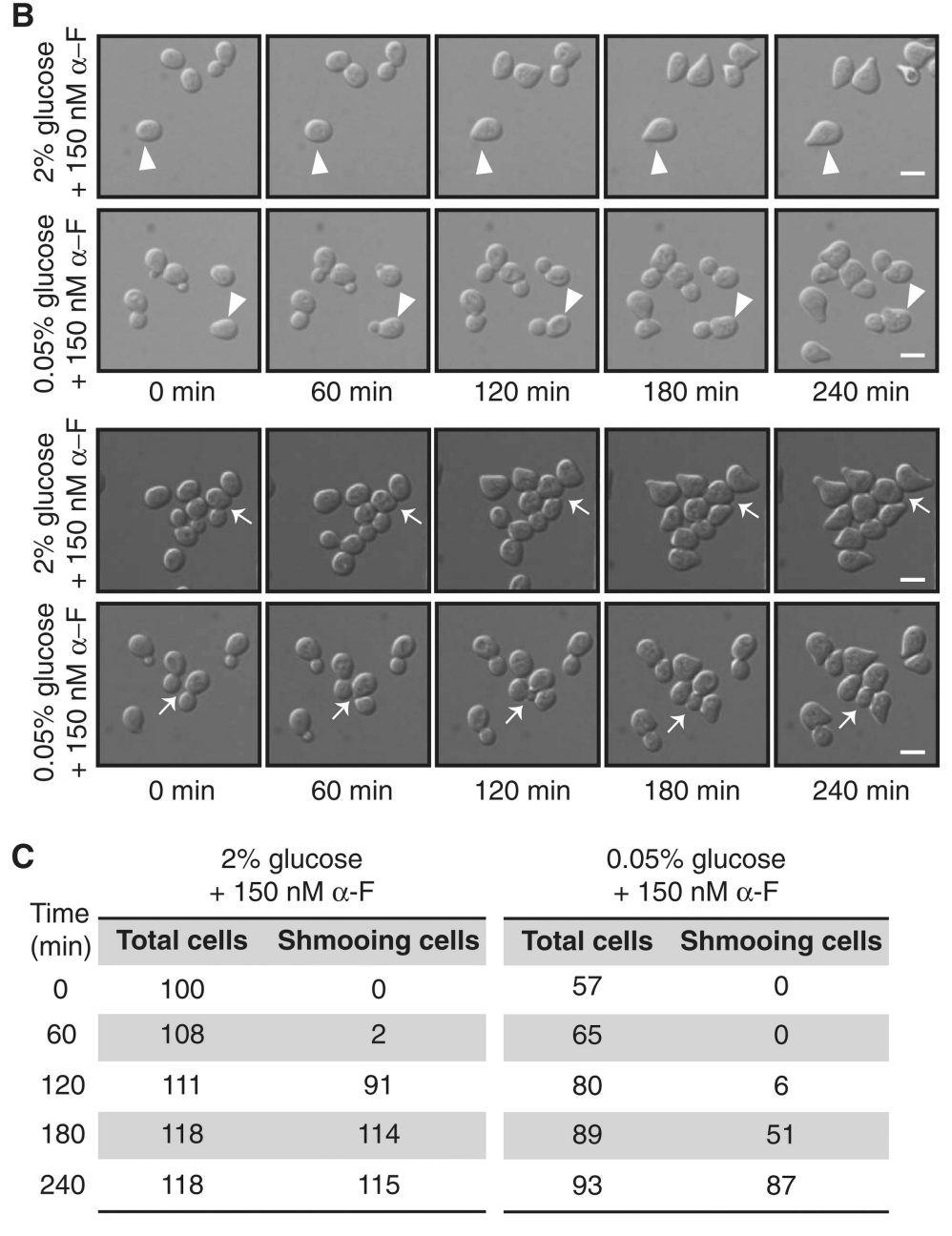

\begin{tabular}{cc}
\multicolumn{2}{c}{$0.05 \%$ glucose } \\
$+150 \mathrm{nM} \alpha-\mathrm{F}$ \\
\cline { 2 - 2 } Total cells & Shmooing cells \\
57 & 0 \\
65 & 0 \\
80 & 6 \\
89 & 51 \\
93 & 87 \\
\hline
\end{tabular}

D

\begin{tabular}{ccc}
\multicolumn{3}{c}{ Budding rate } \\
\hline Glucose & Rate (min) & $\boldsymbol{n}$ \\
$2 \%$ & $122 \pm 2$ & 51 \\
$0.05 \%$ & $118 \pm 2$ & 54 \\
\hline
\end{tabular}

Fig. 5. Shmoo formation and mating are impaired under conditions of limited glucose availability

(A) Mating efficiency assay. Separate cultures of WT mating-type a cells (BY4741) and WT mating-type a cells (BY4742) were grown in medium containing $2 \%$ glucose. Cells $(1 \times$ $10^{7}$ ) from each culture were mixed, filtered onto a nitrocellulose membrane, and incubated on a YPD plate containing either 2 or $0.05 \%$ glucose for 4 hours. Data are means \pm SEM from three independent experiments. (B) WT cells treated for the indicated times with 150 $\mathrm{nM}$ a-F in synthetic complete dextrose (SCD) medium containing 2 or $0.05 \%$ glucose were 
visualized by differential interference contrast microscopy in a microfluidic chamber. The appearance of shmoo projections was monitored after the addition of a-F. Top two rows: Arrowheads indicate cells in $\mathrm{G}_{1}$ phase at the beginning of $\mathrm{a}-\mathrm{F}$ addition. Bottom two rows: Arrows indicate budding cells at the beginning of a-F addition. Scale bars, $5 \mu \mathrm{m}$. (C) Analysis of cell counts for the experiments shown in (A) and (B). (D) Budding rate was determined by measuring the average time for successive buds to emerge in WT cells in a microfluidic chamber in SCD medium containing 2 or $0.05 \%$ glucose. 